\title{
Effect of walnut (Juglans Regia) consumption on hyperlipidemic adults
}

\author{
Shazia ASHRAF ${ }^{1,2}$, Asma ARFEEN ${ }^{1}$, Safeena AMJAD ${ }^{1,2}$, Zaheer AHMED $^{1 \star}$ (1)
}

\begin{abstract}
Present study was aimed to assess effect of walnut kernel with different dose on individuals with hyperlipidemia. Study was conducted at Fatima Memorial Hospital (FMH), Shadman, Lahore, Pakistan and 90 hyperlipidemic individuals were divided into 3 groups having no other disease. Total cholesterol (TC), triglycerides (TG), low density lipoprotein cholesterol (LDL-C) and high density lipoprotein cholesterol (HDL-C) were estimated in all three groups on 0 day (at start) 30th day and on 56th day of study. A significant $(\mathrm{p}<0.05)$ result was observed and blood lipid profile of individuals were seen to improve by consuming walnuts. Group B who were fed $25 \mathrm{~g}$ walnuts kernel per day for 56 days a decrease of $21.6 \%$ in serum TC, $28.9 \%$ in serum TG, $26.5 \%$ in LDL-C; and an increase of $27.1 \%$ in HDL-C was observed as compared to control group. Whereas group C individuals who were fed $50 \mathrm{~g}$ walnut kernel per day showed a decrease of $30.3 \%$ in serum TC, $37.2 \%$ in serum TG, $33.8 \%$ in LDL-C and an increase of $50.0 \%$ in HDL-C was observed. It was concluded that consumption ( $25 \mathrm{~g}$ and $50 \mathrm{~g})$ of walnut kernel showed significant $(\mathrm{p}<0.05)$ improvements in lipid profile of hyperlipidemic individuals when consumed for 56 days.
\end{abstract}

Keywords: cardiovascular disease; hyperlipidemia; omega 3 fatty acids; dyslipidemia; walnuts (Juglans Regia).

Practical Application: Walnut full of nutrients and can contribute significant in health benefits. Especially consumption of 25-50 gram of walnut can be used as adjuvant nutrition for balancing lipids and alleviating early onset of hypertension.

\section{Introduction}

A major risk factor for coronary heart disease (CHD) and atherosclerosis is hyperlipidemia which is prevalent in a significant proportion in the adult population. Between $11.7 \%$ to $41.2 \%$ adults aged $20-39$ and $40-64$ years respectively were found to have high levels of low density lipoprotein cholesterol (LDL-C) but $10.6 \%$ (20-39 years) and $47.7 \%$ (40-64 years) adults who had hyperlipidemia were being treated according to the National Health and Nutrition Examination Survey (NHANES) (Pencina et al., 2014). Cardiovascular diseases are a cause of death worldwide and dyslipidemia is one of the risk factor. In the United States around $45 \%$ of the adult population have $\geq 200 \mathrm{mg} / \mathrm{dL}$ levels of total cholesterol (TC) and 33\% of adults approximately have $>130 \mathrm{mg} / \mathrm{dL}$ levels of low density lipoprotein (LDL) cholesterol where as $16 \%$ only have lower levels of high density lipoprotein (HDL) cholesterol concentration in the blood ( $<40 \mathrm{mg} / \mathrm{dL}$ ) (Maki \& Dicklin, 2020).

Lipid metabolism is affected by the type of lipid consumed through the diet and nuts are packaged with favorable nutrients that have shown to have a positive effect on the lipid profile as they are rich in monounsaturated and polyunsaturated fatty acids (Mushtaq et al., 2013). Omega-3 fatty acids can be attained from several sources. Short-chain omega-3, alpha-linoleic acid (ALA), is establish mostly in plant-based foods (e.g., walnuts, flaxseed, chia seeds). Long-chain omega- 3 fatty acids, docosahexaenoic acid (DHA) and eicosapentaenoic acid (EPA), are predominantly obtained from marine-based foods (e.g., oily fish) (Abdelhamid et al., 2020). Tree nuts are dietary constituents that are known to improve lipid profile and among the tree nuts walnuts are the most common nuts consumed in the world (Hayes et al., 2016). Walnuts are the collective food with the highest content of ALA, the vegetable n-3 fatty acid (Ros et al., 2018). A study suggested that a low cholesterol diet helps to decrease plasma cholesterol levels (Toth, 2004). Moreover, consumption of tree nuts also lowered the body mass index and improve the lipid profile of the adults in a recent study done in the United States (O'Neil et al., 2015). Furthermore, one in three Pakistani adults are either obese or overweight and Pakistan lies among the top 10 countries that contribute to a significant percentage to the obese population in the world (Chester, 2014). Walnuts have a higher polyunsaturated fat content especially alpha linolenic acid (ALA) in combination with tocopherol, an antioxidant compared to other nuts (Storlien et al., 2000). A low fat diet given in combination with walnuts was seen to improve the total cholesterol levels in individuals as compared to an unaccompanied low fat diet (Almario et al., 2001). Furthermore walnut skin contains $6.5 \mathrm{mmol}$ antioxidants, provided by one ounce serving, which is quite high compared to other tree nuts that are consumed (Zhang et al., 2009). Consistent positive effect on reduction of total cholesterol (TC), and low density lipoprotein cholesterol (LDL-C) has also been determined by Griel \& Kris-Etherton (2006). Essential fatty acids, like omega-3 cannot be manufactured in the human body and need to be taken from the diet. Walnuts are rich sources of omega-3 fatty acid and studies have shown that an omega- 3 fatty acid rich diet 
can help to improve triglyceride levels and elevate high density lipoprotein (HDL) cholesterol, which is known to be the good cholesterol also anticoagulant properties are another specialty of the omega-3 fatty acid (Taj et al., 2010). In Pakistan, Punjab is one province where one can find diversity in eating habits. The residents of Lahore are known to live to eat, and they dine out or have a variety of dishes on their dining table very frequently. With that a growing trend of Hyperlipidemia is also seen, many screened and unscreened victims.

It is important to have a healthy lipid profile to protect oneself from the risk of developing degenerative diseases, and easy to follow dietary management needs to be implemented in the population. Therefore, this study was designed to see the effect of walnut consumption on lipid profile of hyperlipidemic patients as walnut is easily available in our community and liked by all age groups.

\section{Materials and methods}

The present study was conducted at Fatima Memorial Hospital, Lahore. The research was an experimental study. It comprised of obtaining initial information including anthropometric data, biochemical analysis, clinical evaluation, dietary and lifestyle information. Based on the baseline parameters the study population was divided into three groups i.e. group A (control), group B (25 g walnut kernel per day) and group C (50 g walnut kernel per day. After the intervention with walnuts, the groups are re-examined biochemically after a mid-point period of 30 days and then at the end point after 56 days. The total study population consisted of 90 individuals. Each group was comprised of thirty (30) individuals.

\subsection{Anthropometric profile}

- Anthropometry including height, weight, and waist to hip ratio were taken. BMI was calculated using the standard Formula 1.

- Body Mass Index (BMI): the standard formula was used to calculate BMI:

$$
\text { BMI }\left(K g / m^{2}\right)=\frac{w e i g h t(K g)}{\operatorname{height}(\boldsymbol{m})^{2}}
$$

\subsection{Biochemical assessment}

Biochemical including 12 hours over night fasting blood samples were taken for total cholesterol (TC), triglyceride (TG), high density lipoprotein (HDL) cholesterol and low density lipoprotein (LDL). $5 \mathrm{~mL}$ of blood sample were drawn three times: 0 day, $30^{\text {th }}$ day and on the $56^{\text {th }}$ day of the study. The study population was divided into three groups that were observed for a total period of 56 days. The experimental group $\mathrm{B}$ was fed $25 \mathrm{~g}$ of walnut kernel per day and group $\mathrm{C}$ was fed $50 \mathrm{~g}$ of walnut kernel per day without any dietary modification whereas the control group (group A) was fed with no walnuts. Blood samples were drawn after a mid-point period of 30 days.
After intervention of 8 weeks ( 56 days) all biochemical tests and clinical evaluation which were initially conducted at baseline were done again. On the $0,30^{\text {th }}$ and $56^{\text {th }}$ day blood samples were drawn for a comparative analysis of the lipid profile between the groups. Percentage change (decrease or increase) was calculated by the following Formula 2:

(Baseline Value - End of Experiment Value)/ Baseline Value $x 100$

\subsection{Statistical analysis}

Data analysis was done by using the SPSS version 20 . ANOVA was applied between the three groups and the $p$ value was set at $<0.05$ ( $95 \%$ of confidence level) to accept or reject the hypothesis if whether consumption of walnuts have an impact on the lipid profile or not.

\section{Results and discussion}

Cardiovascular diseases are a cause of death worldwide and dyslipidemia is one of the risk factor. In the United States around $45 \%$ of the adult population have $\geq 200 \mathrm{mg} / \mathrm{dL}$ levels of total cholesterol (TC) and $33 \%$ of adults approximately have $>130 \mathrm{mg} / \mathrm{dL}$ levels of low density lipoprotein (LDL) cholesterol where as $16 \%$ only have lower levels of high density lipoprotein (HDL) cholesterol concentration in the blood ( $<40 \mathrm{mg} / \mathrm{dL}$ ) (Curd, 2013). The conventional use of statins to manage a normal lipid profile has growing side effects and people are looking for natural remedies that can cure and manage their illness. Nuts, especially walnuts have beneficial effects on the human health and are considered inexpensive and safe to use for treating dyslipidemia. They have significantly shown to reduce blood lipid markers like total cholesterol, LDL and triglycerides and raise HDL- cholesterol. The mechanism behind this is thought to be the reduction of the expression of SREBP- $1 c$ and the rise of PPAR $\alpha$ expression as observed in diabetic rats (Mushtaq et al., 2013). The effects of walnut consumption may depend on the metabolic state, with a neutral effect on insulin sensitivity reported in healthy humans, but reduced insulin resistance described in patients with MetS and in overweight or obese women(Scott et al., 2017). Alterations in the lipid profile have also been associated with age. Estrogen is the major protective hormone in women and that protection is altered by menopause. Estrogen favorably affects the lipid profile. The occurrence of abnormal lipid levels occurs more in men rather than women, but after menopause it becomes more prevalent in the latter. Dietary and life-style factors may influence the age dependency of lipid profile(Manson et al., 2020).

The present study was undertaken due to the fact that in Pakistan no clear dietary indicator or value for a normal or hyperlipidemic individual has been established. This is because the dietary habits of people are quite diverse and no regular checkup is given importance by general public. This results in sudden heart attacks or stroke.

\subsection{Socio demographic profile of patients}

The Figure 1 represent the socio demographic data of the individuals in each group. Group A (control) and group C ( $50 \mathrm{~g} /$ day) 
had $57 \%(n=17)$ males and $43 \%(n=13)$ females whereas group B consisted of $60 \%(n=18)$ males and $40 \%(n=12)$ females. The mean age in the three groups were $38.0 \pm 8.1,37.0 \pm 9.0$ and $38.0 \pm 8.1$ years respectively. $18 \%(n=16)$ had age below 30 years, $29 \%(n=26)$ between 31 to 35 years, $20 \%(n=18)$ between $36-40$ years and $33 \%(n=30)$ above 40 years of age as shown in Figure 1. 70\% ( $n=21)$ of individuals were married in group $A$ and $C$ and $30 \%(n=9)$ unmarried whereas $63 \%(n=19)$ were married in group B and $37 \%(n=11)$ unmarried in group $B$.

\subsection{Nutritional status of subjects}

Figure 2 represent the body mass index data of the individuals in each group. The mean BMI in Group A (control) was $29.4 \pm 5.8 \mathrm{~kg} / \mathrm{m}^{2}, 26.0 \pm 5.3 \mathrm{~kg} / \mathrm{m}^{2}$ in group B (25 g/day) and $27.9 \pm 5.3 \mathrm{~kg} / \mathrm{m}^{2}$ in group C (50 g/day). Moreover, Group A

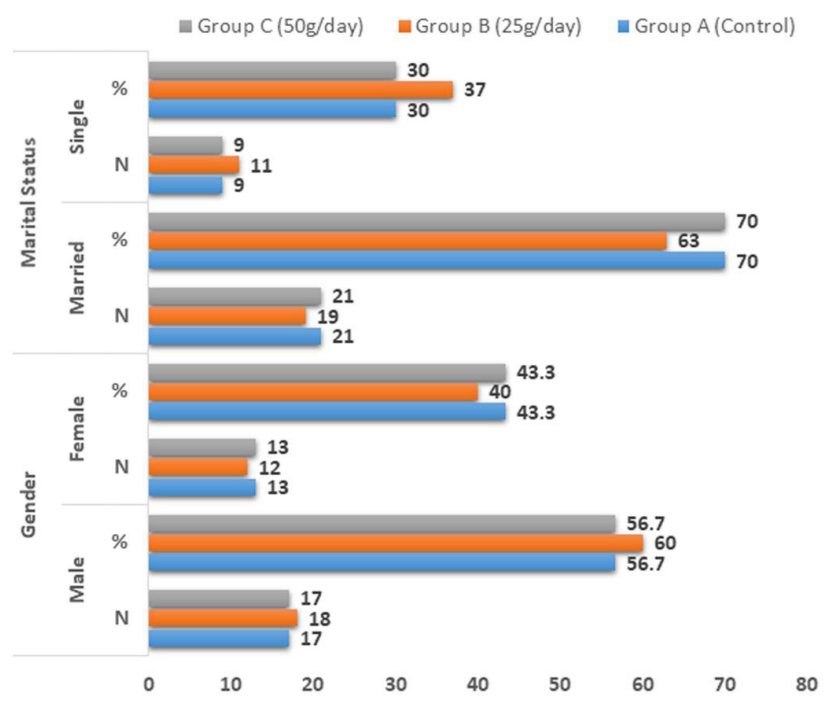

Figure 1. Socio Demographic Profile of the Patients (N: number of patients). (control) had no underweight individuals whereas group B and group $C$ had $10 \%(n=3)$ and $6.7 \%(n=2)$ of individuals who were underweight. 26.7\% $(n=8)$ from group A, 33.3\% $(n=10)$ from group B and 20\% $(n=6)$ from group C had their body mass index in the normal range. A higher $\mathrm{BMI}$ is a risk factor to develop diseases and $33.3 \%(\mathrm{n}=10)$ from group $\mathrm{A}$ and $\mathrm{C}$ and $36.7 \%(\mathrm{n}=11)$ from group B had a BMI greater than $25 \mathrm{~kg} / \mathrm{m}^{2}$ and were categorized as overweight. In the obese category $40 \%(n=12)$ individual were categorized from group A and C and $20 \%(n=6)$ in group B. In the present study there was no significant change observed in bodyweight or BMI of the individuals after consuming $25 \mathrm{~g}$ or $50 \mathrm{~g}$ of walnut kernel for fifty-six days. The results are in line with the research conducted by Katz et al. (2012), who concluded that walnut consumption had no association with bodyweight. Moreover, when walnut supplementation was assessed on postmenopausal women no association was seen between walnut consumption and body weight gain (Almario et al., 2001). However, in a research conducted by Mushtaq et al. (2013) it was found that daily consumption of walnuts resulted a reduction in the body mass index in obese adults.

\subsection{Biochemical assessment of the subjects}

Biochemical analysis was done in the research which included blood lipid profile analysis in which total cholesterol, serum triglyceride, low density lipoprotein cholesterol (LDL-C) and high density lipoprotein cholesterol (HDL-C) levels were monitored on day zero, $30^{\text {th }}$ day and $56^{\text {th }}$ day of the study. The tables below describe the results concluded:

The results presented in Table 1 revealed no significant difference $(p>0.05)$ in total serum cholesterol levels of both the genders. The control had $205.2 \pm 24.9 \mathrm{mg} / \mathrm{dL}$, group B had $203.6 \pm 25.5 \mathrm{mg} / \mathrm{dL}$ and group $\mathrm{C}$ had $207.8 \pm 13.9 \mathrm{mg} / \mathrm{dL}$ which indicated similar mean values on day zero. The serum samples on $30^{\text {th }}$ day in all the tree groups also showed no significant differences as shown in Table 1 with the values $203.1 \pm 25.3 \mathrm{mg} / \mathrm{dL}$

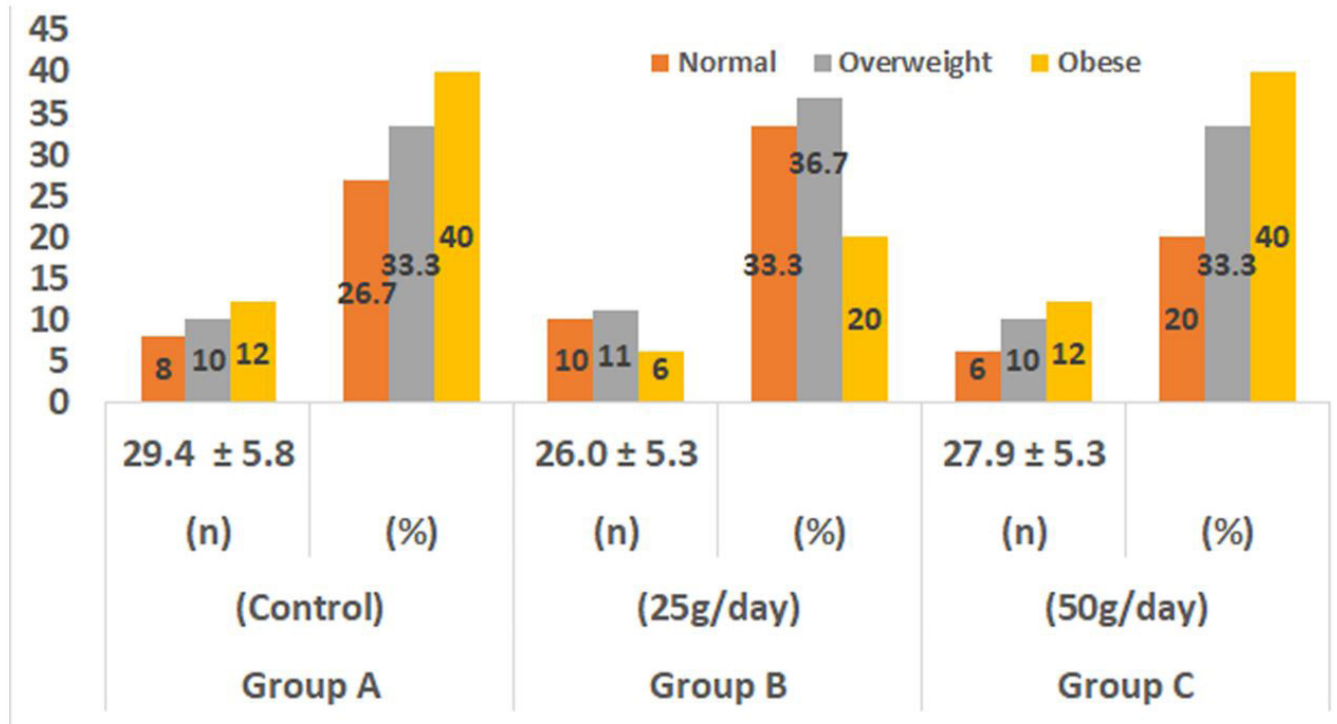

Figure 2. Frequency of Body Mass Index (BMI) of Subjects. 
for group A, $191.0 \pm 24.1 \mathrm{mg} / \mathrm{dL}$ for group B which was fed $25 \mathrm{~g}$ walnut kernel per day and $182.5 \pm 17.3 \mathrm{mg} / \mathrm{dL}$ for group $\mathrm{C}$ which was fed $50 \mathrm{~g}$ of walnut kernel per day. The blood samples taken on the $56^{\text {th }}$ day showed significant differences $(\mathrm{p}<0.05)$ in total cholesterol values in the groups i.e. group B $159.6 \pm 25.2 \mathrm{mg} / \mathrm{dL}$ and C $144.7 \pm 15.2 \mathrm{mg} / \mathrm{dL}$ were significantly lower than the control group similarly group C $144.7 \pm 15.2 \mathrm{mg} / \mathrm{dL}$ was significantly lower than the group B $159.6 \pm 25.2 \mathrm{mg} / \mathrm{dL}$ which was fed $25 \mathrm{~g}$. The lowering in serum cholesterol in control group were just $1 \%$ which may be due to differences in physiology whereas group B decreased cholesterol $21.6 \%$ as compared to control and group C 30.3\% lowering effect as compared to control. The results are similar to a study conducted by Rajaram et al. (2009) who estimated the effect of omega 3 in walnuts kernel on the serum lipid markers and concluded that serum total cholesterol levels in adults who consumed the walnut diet were lower as compared to the adults who consumed the control diet. Furthermore, supplementation of walnuts in obese individuals showed significant decline $(\mathrm{p}<0.05)$ in cholesterol levels in a study conducted in Quetta (Mushtaq et al., 2013). Furthermore, Kwak et al. (2014) in a study reported significant reduction in serum cholesterol levels of individuals who were fed walnut which is confirmatory to the present as well as some other studies that walnut feeding may improve beneficial reduction of serum cholesterol levels which may lead to avoid several cardiovascular disorders.

The results presented in Table 2 revealed no significant difference $(p>0.05)$ in the mean of serum triglyceride levels of both the genders. Group A (control) at $204.0 \pm 39.8 \mathrm{mg} / \mathrm{dL}$, group B $207.1 \pm 64.3 \mathrm{mg} / \mathrm{dL}$ and group C $209.6 \pm 41.7 \mathrm{mg} / \mathrm{dL}$ which indicates similar mean values zero day of the experiment. The serum samples on $30^{\text {th }}$ day in all the three groups shows significant differences as shown in Table 2 with the values $202.8 \pm 38.3 \mathrm{mg} / \mathrm{dL}$ for group A $180.4 \pm 58.8 \mathrm{mg} / \mathrm{dL}$ for group B which was fed $25 \mathrm{~g}$ walnut kernel per day and $171.7 \pm 31.0 \mathrm{mg} / \mathrm{dL}$ for group $\mathrm{C}$ which was fed $50 \mathrm{~g}$ of walnut kernel per day. The samples taken on the $56^{\text {th }}$ day also showed significant differences $(\mathrm{p}<0.05)$ in serum triglyceride values in all the three groups i.e. group B $147.3 \pm 50.6 \mathrm{mg} / \mathrm{dL}$ and group C $131.7 \pm$ $25.5 \mathrm{mg} / \mathrm{dL}$ were significantly lower than the control group $204.3 \pm 40.0 \mathrm{mg} / \mathrm{dL}$. Similarly group C $131.7 \pm 25.5 \mathrm{mg} / \mathrm{dL}$ was significantly lower than that of group B $147.3 \pm 50.6 \mathrm{mg} / \mathrm{dL}$ which was fed $25 \mathrm{~g}$.

The lowering in serum triglycerides in control group were just $0.1 \%$ which may be due to differences in physiology whereas group B decreased triglycerides $28.9 \%$ as compared to control and group $\mathrm{C}$ has $37.2 \%$ lowering effect as compared to control. The data indicated that feeding walnuts at both levels for 30 and 56 days had significant lowering effect on serum triglyceride levels of hyperlipidemic adults. In a research, diet supplemented with walnuts significantly reduced plasma triglyceride concentrations (Kwak et al., 2014). Wu et al. (2014) in his research concluded that a diet enriched with walnuts ( $43 \mathrm{~g} /$ day) did not have a significant effect in decreasing the serum triglyceride levels of individuals $(\mathrm{P}=0.323)$. Similarly no significant effect on triglyceride concentration was observed when individuals were fed with a walnut rich diet when compared to a control $(\mathrm{P}=0.3)$ (Banel \& Hu, 2009).

The results presented in Table 3 revealed no significant difference $(p>0.05)$ in the mean of serum LDL-cholesterol levels of both the genders. Group A (control) at $174.0 \pm 20.0 \mathrm{mg} / \mathrm{dL}$, group B $176.1 \pm 22.0 \mathrm{mg} / \mathrm{dL}$ and group C $178.6 \pm 20.0 \mathrm{mg} / \mathrm{dL}$ which indicated similar mean values at the zero day of the experiment. The serum samples on $30^{\text {th }}$ day in all the three groups showed significant differences as shown in Table 3 with the values $174.7 \pm 19.2 \mathrm{mg} / \mathrm{dL}$ for group A $155.7 \pm 24.9 \mathrm{mg} / \mathrm{dL}$ for group B which was fed $25 \mathrm{~g}$ walnut kernel per day and $145.2 \pm$ $22.0 \mathrm{mg} / \mathrm{dL}$ for group $\mathrm{C}$ which was fed $50 \mathrm{~g}$ of walnut kernel per

Table 1. Total cholesterol levels of study subjects at different times during study.

\begin{tabular}{|c|c|c|c|c|c|}
\hline & & & Total C & $(\mathrm{mg} / \mathrm{dL})$ & \\
\hline & & Group A & Group B & Group C & n-volue \\
\hline Mid (30 $30^{\text {th }}$ day) & Mean \pm S.D & $203.1 \pm 25.3$ & $191.0 \pm 24.1$ & $182.5 \pm 17.3$ & 0.165 \\
\hline At the end ( $56^{\text {th }}$ day) & Mean \pm S.D & $203.3 \pm 26.0$ & $159.6 \pm 25.2$ & $144.7 \pm 15.2$ & 0.003 \\
\hline
\end{tabular}

S.D: Standard deviation, p-value: level of significance.

Table 2. Serum Triglyceride levels study subjects at different times during study.

\begin{tabular}{|c|c|c|c|c|c|}
\hline & & & Serum T & $(\mathrm{mg} / \mathrm{dL})$ & \\
\hline & & Group A & Group B & Group C & n-value \\
\hline & Mean $+\mathrm{SD}$ & & & & \\
\hline $\operatorname{Mid}\left(30^{\text {th }} \mathrm{dav}\right)$ & Menn $+C D$ & $2020+203$ & $1004+508$ & $1717+210$ & 0 \\
\hline 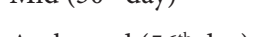 & & $202.0 \pm 50.5$ & $100.4 \pm 0.0$ & $171.1+51.0$ & $0.02 J$ \\
\hline At the end ( $56^{\text {th }}$ day) & Mean \pm SD & $204.3 \pm 40.0$ & $147.3 \pm 50.6$ & $131.7 \pm 25.5$ & $<0.001$ \\
\hline \% Decrease & & 0.1 & 28.9 & 37.2 & \\
\hline
\end{tabular}


day. The samples taken on the $56^{\text {th }}$ day also showed significant differences $(\mathrm{p}<0.05)$ in LDL-cholesterol values in all the three groups i.e. group B $129.3 \pm 47.9 \mathrm{mg} / \mathrm{dL}$ and group C $118.3 \pm$ $13.2 \mathrm{mg} / \mathrm{dL}$ were significantly lower than the control group $177.4 \pm 19.8 \mathrm{mg} / \mathrm{dL}$. Similarly, group C $118.3 \pm 13.2 \mathrm{mg} / \mathrm{dL}$ was significantly lower than the group B $129.3 \pm 47.9 \mathrm{mg} / \mathrm{dL}$ which was fed $25 \mathrm{~g}$ of walnuts per day. The lowering in LDL-cholesterol levels in control group were just $2 \%$ which may be due to differences in physiology whereas group B decreased LDL-C $26.5 \%$ as compared to control and group C has $33.8 \%$ lowering effect as compared to control. The data indicated that feeding walnuts at both levels for 30 and 56 days had significant lowering effect on LDL-cholesterol levels of hyperlipidemic adults. The LDL cholesterol when monitored after a supplementation of walnuts in the diet, a significant reduction was seen in the serum levels in females $(\mathrm{P}=0.0008)$ whereas no significant change was observed in males ( $\mathrm{P}=0.078)$ (Iwamoto et al., 2002). Furthermore, Damasceno et al. (2011) in his research observed a decline in LDL-cholesterol from the baseline by $10.8 \%$ after the participants were fed with a walnut and almond diet. Similarly, LDL cholesterol in healthy individuals significantly decreased from 123.80 to $108.63 \mathrm{mmol} / \mathrm{L}(13.9 \%, \mathrm{P}<0.01)$ after being fed with $40 \mathrm{~g}$ walnut kernel per day (Kalantarian et al., 2015).

The results presented in Table 4 reveal no significant difference ( $p>0.05)$ in the mean of serum HDL-cholesterol levels of both the genders. The group A (control) at $48.6 \pm 10.1 \mathrm{mg} / \mathrm{dL}$, group B $47.9 \pm 5.7 \mathrm{mg} / \mathrm{dL}$ and group C $47.5 \pm 5.4 \mathrm{mg} / \mathrm{dL}$ which indicates similar mean values at the beginning of the experiment. The serum samples on $30^{\text {th }}$ day in all the three groups showed significant differences as shown in Table 4 with the values $48.2 \pm 8.6 \mathrm{mg} / \mathrm{dL}$ for group A $53.4 \pm 5.5 \mathrm{mg} / \mathrm{dL}$ for group B which was fed $25 \mathrm{~g}$ and $61.1 \pm 6.7 \mathrm{mg} / \mathrm{dL}$ for group $\mathrm{C}$ which was fed $50 \mathrm{~g}$ of walnut kernel per day. The samples taken on the $56^{\text {th }}$ day also showed significant differences $(\mathrm{p}<0.05)$ in HDL-cholesterol values in all the three groups i.e. group B $60.9 \pm 5.3 \mathrm{mg} / \mathrm{dL}$ and group
C $71.2 \pm 5.1 \mathrm{mg} / \mathrm{dL}$ were significantly higher than the control group $46.0 \pm 8.9 \mathrm{mg} / \mathrm{dL}$. Similarly, group C $71.2 \pm 5.1 \mathrm{mg} / \mathrm{dL}$ was significantly higher than the group B $60.9 \pm 5.3 \mathrm{mg} / \mathrm{dL}$ which was fed $25 \mathrm{~g}$. The increase in HDL-cholesterol levels in control group were just $2 \%$ which may be due to differences in physiology whereas group B increased HDL-C 27.1\% as compared to control and group $\mathrm{C}$ has $50.0 \%$ increasing effect as compared to control. The data indicated that feeding walnuts at both levels for 30 and 56 days had significant raising effect on HDL-cholesterol levels of hyperlipidemic adults. Similarly, Tapsell et al. (2004) in his study observed a significant increase in the plasma HDL-cholesterol concentration $(\mathrm{P}=0.046)$ and the HDL cholesterol to total cholesterol ratio $(\mathrm{P}=0.049)$ in the group that was fed walnuts. Moreover, frequent consumption of walnuts resulted in a significant incline in HDL cholesterol from the baseline by $9 \%$ (Zibaeenezhad et al., 2005). Furthermore, when $30 \mathrm{~g}$ of walnuts were fed to hyperlipidemic patients it was observed that HDLcholesterol increased by $6.3 \mathrm{mg} / \mathrm{dL}$ (Tufail et al., 2015). However, where walnuts were seen to reduced total cholesterol, triglyceride and LDL cholesterol levels after walnut supplementation, no significant effect was noted in improving the serum concentration of HDL cholesterol (Kwak et al., 2014). Walnuts have many plant chemicals which add their overall importance related to antioxidants including melatonin, salicylic acid, vitamin E, carotenoids and polyphenols. These compounds have potential health effects on cancer, aging, inflammation and neurological disorders. Normally consumption of 6 to 7 nuts of regular size in a day can relief to remove diseases that cause free radicals in the body. The lowering in LDL-cholesterol levels in control group were just $2 \%$ in the present study which may be due to differences in physiology whereas group B which was fed $25 \mathrm{~g}$ of walnut kernel per day decreased LDL-C by $26.5 \%$ as compared to control and group $\mathrm{C}$ which was fed $50 \mathrm{~g}$ of walnut kernel per day has $33.8 \%$ lowering effect as compared to control. The data indicated that feeding walnuts at both levels for 30 and 56 days had significant lowering effect on LDL-cholesterol levels of

Table 3. Serum LDL Cholesterol of study subjects at different times during study.

\begin{tabular}{|c|c|c|c|c|c|}
\hline & & & LDL-C & $(\mathrm{mg} / \mathrm{dL})$ & \\
\hline & & Group A & Group B & Group C & n-volue \\
\hline Baseline ( 0 day) & & & & & \\
\hline Daseninte (U Gay) & Mean \pm S.D & $1 / 4.0 \pm 20.0$ & $1 / 0.1 \pm 22.0$ & $1 / 8.0 \pm 20.0$ & 0.450 \\
\hline Mid (30 $30^{\text {th }}$ day) & Mean \pm S.D & $174.7 \pm 19.2$ & $155.7 \pm 24.9$ & $145.2 \pm 22.0$ & $<0.001$ \\
\hline At the end ( $56^{\text {th }}$ day) & Mean \pm S.D & $177.4 \pm 19.8$ & $129.3 \pm 47.9$ & $118.3 \pm 13.2$ & $<0.001$ \\
\hline$\%$ Decrease & & 2.0 & 26.5 & 33.8 & \\
\hline
\end{tabular}

Table 4. Serum HDL cholesterol of study subjects at different times during study.

\begin{tabular}{lccccc}
\hline & & \multicolumn{2}{c}{ HDL-Cholesterol (mg/dL) } \\
\cline { 3 - 6 } & & Group A & Group B & Group C \\
& & Control & 50 g/day & p-value \\
\hline Baseline (0 day) & Mean \pm S.D & $48.6 \pm 10.1$ & $47.9 \pm 5.7$ & $47.5 \pm 5.4$ & 0.844 \\
Mid (30 ${ }^{\text {th }}$ day) & Mean \pm S.D & $48.2 \pm 8.6$ & $53.4 \pm 5.5$ & $61.1 \pm 6.7$ & 0.000 \\
At the end $\left(56^{\text {th }}\right.$ day) & Mean \pm S.D & $46.0 \pm 8.9$ & $60.9 \pm 5.3$ & $71.2 \pm 5.1$ & 5.0 \\
\% Increase & & 2.0 & 27.1 & 50.0 & 0.000 \\
\hline
\end{tabular}


hyperlipidemic individuals. Dietary supplementation with essential fatty acids has been shown to have beneficial effects within the human body including hypelipidemia (Carey et al., 2020).

In current research, the increase in HDL-cholesterol levels in control group was $2 \%$ which may be due to differences in physiology whereas group B increased HDL-C $27.1 \%$ as compared to control and group $\mathrm{C}$ has $50.0 \%$ increasing effect as compared to control. The data indicated that feeding walnuts at both levels for 30 or 56 days had significant raising effect on HDL-cholesterol levels of hyperlipidemic adults.

\section{Conclusion}

Tree nuts especially walnuts are super food packed with beneficial nutrients that help in lowering and improving the lipid profile including total cholesterol, serum triglyceride, low density lipoprotein cholesterol (LDL-C) and high density lipoprotein cholesterol (HDL-C) significantly $(\mathrm{p}<0.05)$ in hyperlipidemic individuals when fed in doses $25 \mathrm{~g}$ and $50 \mathrm{~g}$ for a period of 56 days. Walnuts are highly recommended to be added in the daily diet for its numerous health benefits.

\section{Acknowledgements}

The data was collected by the department of NUR-FMS School of Nutrition at Fatima Memorial Hospital Lahore, Pakistan. We wish to thank the Patients for their cooperation.

\section{References}

Abdelhamid, A. S., Brown, T. J., Brainard, J. S., Biswas, P., Thorpe, G. C., Moore, H. J., Deane, K. H., Summerbell, C. D., Worthington, H. V., Song, F., \& Hooper, L. (2020). Omega-3 fatty acids for the primary and secondary prevention of cardiovascular disease. Cochrane Database of Systematic Reviews, 3, 3. http://dx.doi.org/10.1002/14651858. CD003177.pub5. PMid:32114706.

Almario, R. U., Vonghavaravat, V., Wong, R., \& Kasim-Karakas, S. E. (2001). Effects of walnut consumption on plasma fatty acids and lipoproteins in combined hyperlipidemia. The American Journal of Clinical Nutrition, 74(1), 72-79. http://dx.doi.org/10.1093/ ajcn/74.1.72. PMid:11451720.

Banel, D. K., \& Hu, F. B. (2009). Effects of walnut consumption on blood lipids and other cardiovascular risk factors: a meta-analysis and systematic review. The American Journal of Clinical Nutrition, 90(1), 56-63. http://dx.doi.org/10.3945/ajcn.2009.27457. PMid:19458020.

Carey, A. N., Fisher, D. R., Bielinski, D. F., Cahoon, D. S., \& ShukittHale, B. (2020). Walnut-associated fatty acids inhibit LPS-induced activation of BV-2 microglia. Inflammation, 43(1), 241-250. http:// dx.doi.org/10.1007/s10753-019-01113-y. PMid:31741196.

Chester, K. (2014). Overview of the BioSense 2.0 system architecture. Online Journal of Public Health Informatics, 6(1). http://dx.doi. org/10.5210/ojphi.v6i1.5145.

Curd, C. K. (2013). Effects of strawberries on lipid profiles and biomarkers of lipid oxidation in subjects with dyslipidemia and abdominal adiposity. Oklahoma: Oklahoma State University.

Damasceno, N., Pérez-Heras, A., Serra, M., Cofán, M., Sala-Vila, A., Salas-Salvadó, J., \& Ros, E. (2011). Crossover study of diets enriched with virgin olive oil, walnuts or almonds. Effects on lipids and other cardiovascular risk markers. Nutrition, Metabolism, and Cardiovascular Diseases, 21(Suppl. 1), S14-S20. http://dx.doi. org/10.1016/j.numecd.2010.12.006. PMid:21421296.

Griel, A. E., \& Kris-Etherton, P. M. (2006). Tree nuts and the lipid profile: a review of clinical studies. British Journal of Nutrition, 96(Suppl. 2), S68-S78. http://dx.doi.org/10.1017/BJN20061866. PMid:17125536.

Hayes, D., Angove, M. J., Tucci, J., \& Dennis, C. (2016). Walnuts (Juglans regia) chemical composition and research in human health. Critical Reviews in Food Science and Nutrition, 56(8), 1231-1241. http:// dx.doi.org/10.1080/10408398.2012.760516. PMid:25747270.

Iwamoto, M., Imaizumi, K., Sato, M., Hirooka, Y., Sakai, K., Takeshita, A., \& Kono, M. (2002). Serum lipid profiles in Japanese women and men during consumption of walnuts. European Journal of Clinical Nutrition, 56(7), 629-637. http://dx.doi.org/10.1038/sj.ejcn.1601400. PMid:12080402.

Kalantarian, G., Rezaei, M., Homayonfar, S., \& Gharibi, M. (2015). Effect of walnut consumption on serum lipid profiles, high-sensitivity C-reactive protein and nitric oxide in patients with coronary artery disease. Jentashapir Journal of Health Research, 6(1). http://dx.doi. org/10.5812/jjhr.27196.

Katz, D. L., Davidhi, A., Ma, Y., Kavak, Y., Bifulco, L., \& Njike, V. Y. (2012). Effects of walnuts on endothelial function in overweight adults with visceral obesity: a randomized, controlled, crossover trial. Journal of the American College of Nutrition, 31(6), 415-423. http://dx.doi.org/10.1080/07315724.2012.10720468. PMid:23756586.

Kwak, J. S., Park, M., \& Kwon, O. (2014). The effect of walnut (Juglans regia $\mathrm{L}$.) intake on improvement of blood lipid levels and vascular health: a meta-analysis. Journal of Nutrition and Health, 47(4), 236246. http://dx.doi.org/10.4163/jnh.2014.47.4.236.

Maki, K. C., \& Dicklin, M. R. (2020). Omega-3 fatty acid therapy for cardiovascular disease: justified or not? Current Opinion in Cardiology, 35(4), 417-422. http://dx.doi.org/10.1097/HCO.0000000000000741. PMid:32412960.

Manson, J. E., Bassuk, S. S., Cook, N. R., Lee, I.-M., Mora, S., Albert, C. M., \& Buring, J. E. (2020). Vitamin D, Marine n-3 fatty acids, and primary prevention of cardiovascular disease current evidence. Circulation Research, 126(1), 112-128. http://dx.doi.org/10.1161/ CIRCRESAHA.119.314541. PMid:31895658.

Mushtaq, R., Mushtaq, R., Khwaja, S., \& Khan, Z. T. (2013). Walnut trim down lipid profile and bmi in obese male in different ethnic groups of Quetta population, Pakistan. Food and Nutrition Sciences, 4(10), 1069-1075. http://dx.doi.org/10.4236/fns.2013.410139.

O’Neil, C. E., Fulgoni, V. L. 3rd, \& Nicklas, T. A. (2015). Tree Nut consumption is associated with better adiposity measures and cardiovascular and metabolic syndrome health risk factors in US Adults: NHANES 2005-2010. Nutrition Journal, 14(1), 64. http:// dx.doi.org/10.1186/s12937-015-0052-x. PMid:26123047.

Pencina, M. J., Navar-Boggan, A. M., D’Agostino, R. B. Sr., Williams, K., Neely, B., Sniderman, A. D., \& Peterson, E. D. (2014). Application of new cholesterol guidelines to a population-based sample. The New England Journal of Medicine, 370(15), 1422-1431. http://dx.doi. org/10.1056/NEJMoa1315665. PMid:24645848.

Rajaram, S., Haddad, E. H., Mejia, A., \& Sabate, J. (2009). Walnuts and fatty fish influence different serum lipid fractions in normal to mildly hyperlipidemic individuals: a randomized controlled study. The American Journal of Clinical Nutrition, 89(5), 1657S-1663S. http:// dx.doi.org/10.3945/ajcn.2009.26736S. PMid:19339404.

Ros, E., Izquierdo-Pulido, M., \& Sala-Vila, A. (2018). Beneficial effects of walnut consumption on human health: Role of micronutrients. Current Opinion in Clinical Nutrition and Metabolic Care, 21(6), 498-504. http://dx.doi.org/10.1097/MCO.0000000000000508. PMid:30199393. 
Scott, N. J., Ellmers, L. J., Pilbrow, A. P., Thomsen, L., Richards, A. M., Frampton, C. M., \& Cameron, V. A. (2017). Metabolic and blood pressure effects of walnut supplementation in a mouse model of the metabolic syndrome. Nutrients, 9(7), 722. http://dx.doi.org/10.3390/ nu9070722. PMid:28686204.

Storlien, L. H., Tapsell, L. C., \& Calvert, G. D. (2000). Role of dietary factors: macronutrients. Nutrition Reviews, 58(3), S7-S9. PMid:10812927.

Taj, M. K., Cheema, A. M., \& Hassani, I. T. (2010). Lipid Profile in Supplementation Walnut and Almond in Hypertension Subjects. Pakistan Journal of Medical \& Health Sciences, 4(3), 172-174.

Tapsell, L. C., Gillen, L. J., Patch, C. S., Batterham, M., Owen, A., Baré, M., \& Kennedy, M. (2004). Including walnuts in a low-fat/modified-fat diet improves HDL cholesterol-to-total cholesterol ratios in patients with type 2 diabetes. Diabetes Care, 27(12), 2777-2783. http://dx.doi. org/10.2337/diacare.27.12.2777. PMid:15562184.

Toth, P. P. (2004). High-density lipoprotein and cardiovascular risk. Circulation, 109(15), 1809-1812. http://dx.doi.org/10.1161/01. CIR.0000126889.97626.B8. PMid:15096460.
Tufail, S., Fatima, A., Niaz, K., Qusoos, A., \& Murad, S. (2015). Walnuts increase good cholesterol (HDL-Cholesterol) and prevent coronary artery disease. Pakistan Journal of Medical \& Health Sciences, 9(4), 1244-1246.

Wu, L., Piotrowski, K., Rau, T., Waldmann, E., Broedl, U. C., Demmelmair, H., Koletzko, B., Stark, R. G., Nagel, J. M., Mantzoros, C. S., \& Parhofer, K. G. (2014). Walnut-enriched diet reduces fasting non-HDLcholesterol and apolipoprotein B in healthy Caucasian subjects: a randomized controlled cross-over clinical trial. Metabolism: Clinical and Experimental, 63(3), 382-391. http://dx.doi.org/10.1016/j. metabol.2013.11.005. PMid:24360749.

Zhang, Z., Liao, L., Moore, J., Wu, T., \& Wang, Z. (2009). Antioxidant phenolic compounds from walnut kernels (Juglans regia L.). Food Chemistry, 113(1), 160-165. http://dx.doi.org/10.1016/j. foodchem.2008.07.061.

Zibaeenezhad, M., Shamsnia, S., \& Khorasani, M. (2005). Walnut consumption in hyperlipidemic patients. Angiology, 56(5), 581-583. http://dx.doi.org/10.1177/000331970505600509. PMid:16193197. 